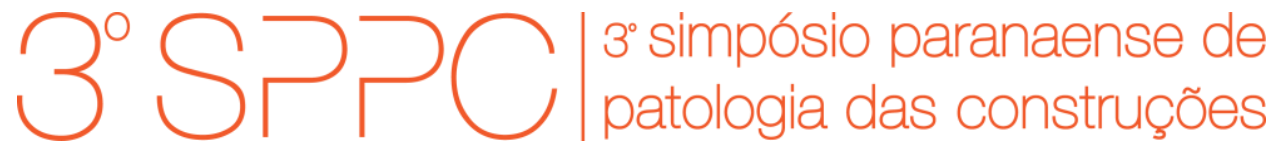

ISSN 2526-7248 artigo n. 3SPPC1017, pp. 186-197, 2018

\title{
Nitrato de prata como método colorimétrico para detecção da penetração de cloretos: análise crítica
}

\author{
Medeiros, Marcelo Henrique Farias de'; Réus, Giovana Costa²; Pontes, Carla \\ Vieira ${ }^{3}$. \\ ${ }^{1}$ Professor, Universidade Federal do Paraná, medeiros.ufpr@gmail.com \\ ${ }^{2}$ Doutoranda, Universidade Federal do Paraná, gio_reus@yahoo.com.br \\ ${ }^{3}$ Graduanda, Universidade Federal do Paraná, carlavieirap97@gmail.com
}

Resumo: Os métodos colorimétricos para avaliação de estruturas de concreto são métodos visuais de inspeção que são utilizados para a identificação de agentes deletérios ou produtos de reações nocivas. Para identificação da presença de íons cloreto existe o método de aspersão de solução de nitrato de prata $\left(\mathrm{AgNO}_{3}\right)$. Após aspersão do $\mathrm{AgNO}_{3}$ sobre o testemunho de concreto é formada uma precipitação esbranquiçada de $\mathrm{AgCl}$ nas regiões com presença de cloretos, e nas regiões onde não há íons cloreto, há o surgimento de uma coloração marrom. O objetivo desta pesquisa é mostrar que existe a possibilidade de ocorrer "falso positivo" no emprego deste método colorimétrico em estruturas reais. O método consistiu em usar corpos de prova de concreto carbonatado como objeto de emprego de aspersão com solução de $\mathrm{AgNO}_{3}$. Os resultados mostram que existem interferência da carbonatação nesta técnica e que aspergir previamente uma solução de hidróxido de cálcio não funciona como meio de viabilizar o uso da técnica.

Palavras-chave: Nitrato de prata, Cloretos, Método colorimétrico, Inspeção de estruturas, Concreto armado.

Abstract: Colorimetric methods for evaluating concrete structures are visual inspection methods that are used to identify deleterious agents or harmful reactions products. The silver nitrate solution $\left(\mathrm{AgNO}_{3}\right)$ is sprayed to identify presence of chloride ions. After spraying of the $\mathrm{AgNO}_{3}$ on concrete, a whitish precipitation of $\mathrm{AgCl}$ appears in zones with the chlorides, and in areas where there are no chloride ions, a brown color appears. This paper aims to show that it is possible to occur "false positive" using this colorimetric method in real structures. The method consisted of using carbonated concrete specimens as an object of sprinkling with $\mathrm{AgNO}_{3}$ solution. The results show that carbonation interfere this technique results and that pre-spraying a calcium hydroxide solution does not work as a means of making the use of the technique practicable.

Keywords: Silver nitrate, Chlorides, Colorimetric method, Inspection of structures, Reinforced concrete. 


\section{Introdução}

O desenvolvimento do método colorimétrico por aspersão de nitrato de prata teve início na Itália, em 1970, por Collepardi. Consiste em um método qualitativo para identificar a presença de cloretos livres em materiais com base cimentícia [1, 2]. 0 método chegou a ser normalizado na Itália, entretanto, segundo Colombo (2001) apud Jucá (2002) [3], por não apresentar resultados seguros, a norma "UNI 7928" foi retirada de operação sem previsão de substituição.

A principal aplicação do método colorimétrico é a determinação da profundidade da frente de penetração de cloretos que ingressam no concreto pelos fenômenos da absorção associada a difusão. Quando a solução de nitrato de prata é aspergida na superfície do concreto, ocorre uma reação fotoquímica (Figura 1). Onde há presença de cloretos livres ocorre a formação de um precipitado branco de cloreto de prata. Na região sem cloretos ou com cloretos combinados, há formação de um precipitado marrom, o óxido de prata.

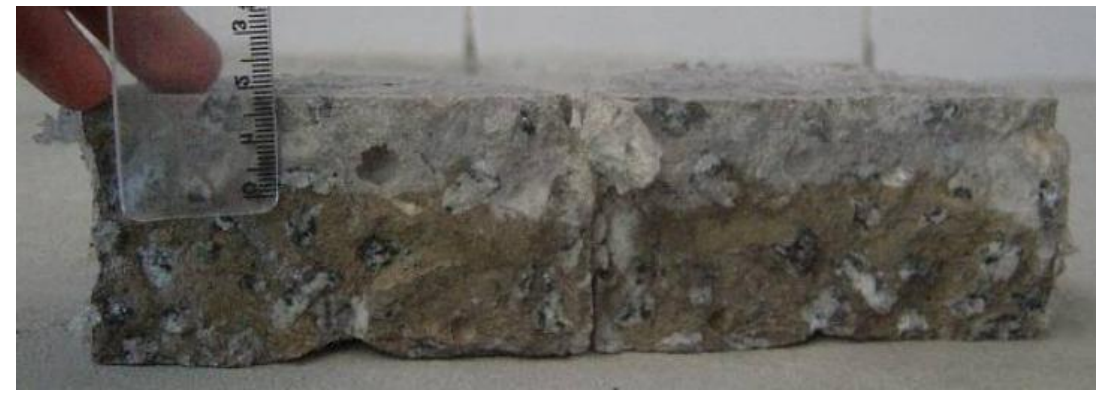

Figura 1: Precipitação de cloretos livres (branco) e cloretos combinados (marrom) [4]

Como a penetração de cloretos não é uniforme, a NT BUILD 492 [5] recomenda realizar sete medidas a cada $10 \mathrm{~mm}$, sendo o resultado a média entre todas elas (Figura 2). No caso de impossibilidade de leitura pela presença de agregados, devese alterar o ponto de medição ou ignorar esta profundidade se houver outras cinco válidas.

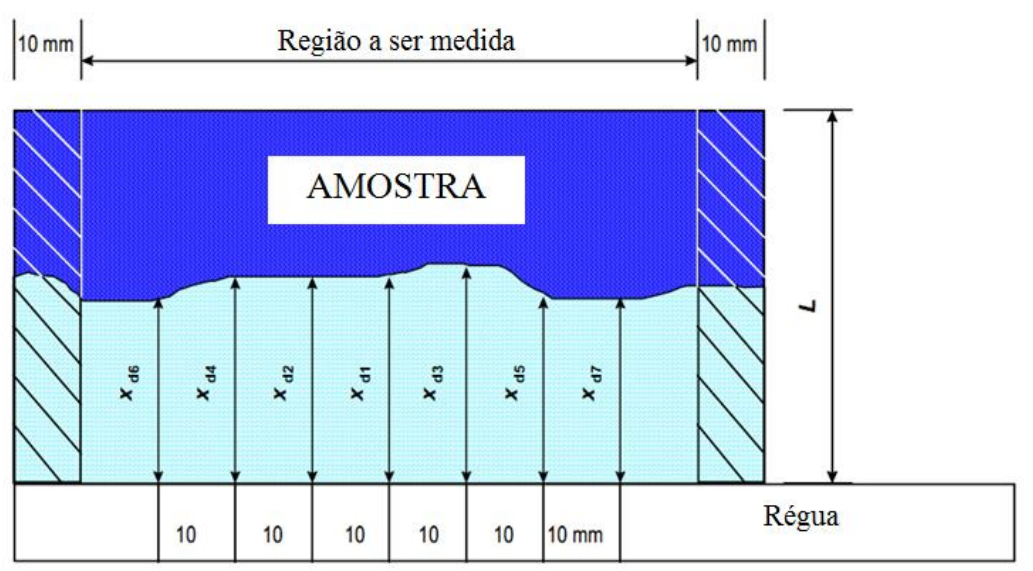

Figura 2: Medidas da frente de penetração de cloretos [5] 
Na região onde há cloretos livres, ocorre a reação química (1). Porém, na presença de carbonatos também há formação de um precipitado branco, conforme indica a reação (2). Por isso, aconselha-se o emprego da técnica de realcalinização do material cimentício antes a aplicação do método colorimétrico [3], pois caso o concreto esteja carbonatado e sem contaminação por cloretos o ensaio pode resultar em "falso positivo", sendo este um dos motivos de dificuldade de implementação desta técnica correntemente nas inspeções de campo.

$$
\begin{aligned}
& \mathrm{AgNO}_{3}+\mathrm{Cl}^{-} \rightarrow \mathrm{AgCl} \downarrow+\mathrm{NO}_{3} \Rightarrow \text { branco } \\
& 2 \mathrm{Ag}^{+}+\mathrm{CO}_{3}^{2-} \rightarrow \mathrm{Ag}_{2} \mathrm{CO}_{3} \downarrow \Rightarrow \text { branco }
\end{aligned}
$$

É dentro deste contexto que se insere este trabalho, tentar confirmar a tendência a ocorrer o "falso positivo", já citado e implementar a ideia de usar solução saturada de hidróxido de cálcio para viabilizar o emprego do método em inspeções reais em que o processo de carbonatação está presente de forma inerente.

\section{Metodologia}

Este trabalho foi desenvolvido focando na possibilidade de usar a aspersão de solução saturada de $\mathrm{Ca}(\mathrm{OH}) 2$ como tratamento prévio para evitar a ocorrência de "falso positivo" quando se usa solução de nitrato de prata como indicador colorimétrico para mensurar a profundidade de penetração dos cloretos livres no concreto.

Para isso, avaliou-se dois traços de concreto com adições minerais (um com atividade pozolânica e outra não reativa).

\subsection{Materiais}

Os corpos de prova cilíndricos de concreto empregados em ambas as fases da presente pesquisa foram dosados com cimento do tipo CPV - ARI, com as dimensões de 100 mm de diâmetro e 200 mm de altura.

As adições minerais utilizadas foram metacaulim e fíler de quartzo, sendo a primeira uma adição pozolânica (reativa) e a segunda, uma adição inerte. As características físicas do cimento, do metacaulim e do fíler de quartzo, assim como a pozolanicidade dessas adições estão representados na

Tabela 1.

Tabela 1: Características físicas e atividade pozolânica das adições minerais

\begin{tabular}{|c|c|c|c|}
\hline & $\begin{array}{c}\text { Massa específica } \\
\left(\mathrm{g} / \mathrm{cm}^{3}\right)\end{array}$ & $\begin{array}{c}\text { Área específica } \\
\mathrm{BET}\left(\mathrm{m}^{2} / \mathrm{kg}\right)\end{array}$ & $\begin{array}{c}\text { Atividade pozolânica } \\
\text { Chapelle modificado } \\
{\left[\mathrm{mg} \mathrm{Ca}(\mathrm{OH})_{2} / \mathrm{g}\right]}\end{array}$ \\
\hline CPV-ARI & 3,09 & 1,070 & - \\
\hline Metacaulim & 2,50 & 23,259 & 1.193 \\
\hline Fíler quatzoso & 2,60 & 1,227 & 140 \\
\hline
\end{tabular}


O resultado do ensaio Chapelle modificado [6] representa a capacidade que o material tem de fixar $\mathrm{Ca}(\mathrm{OH}) 2$. Quanto maior o consumo de $\mathrm{Ca}(\mathrm{OH}) 2$ por grama de adição mineral, maior a sua atividade pozolânica. De acordo com a NBR 15895 [6], para ser qualificada como pozolana, a adição deve consumir mais que $436 \mathrm{mg}$ $\mathrm{Ca}(\mathrm{OH}) 2 / \mathrm{g}$ adição. Desse modo, o fíler quartzoso não é classificado como material pozolânico, enquanto o metacaulim possui elevada pozolanicidade. A Figura 3 corrobora com esta informação mostrando que o difratograma do metacaulim apresenta um halo amorfo típico de pozolanas, enquanto no caso do fíler quartzoso não existe o halo, indicando que o material é cristalino.
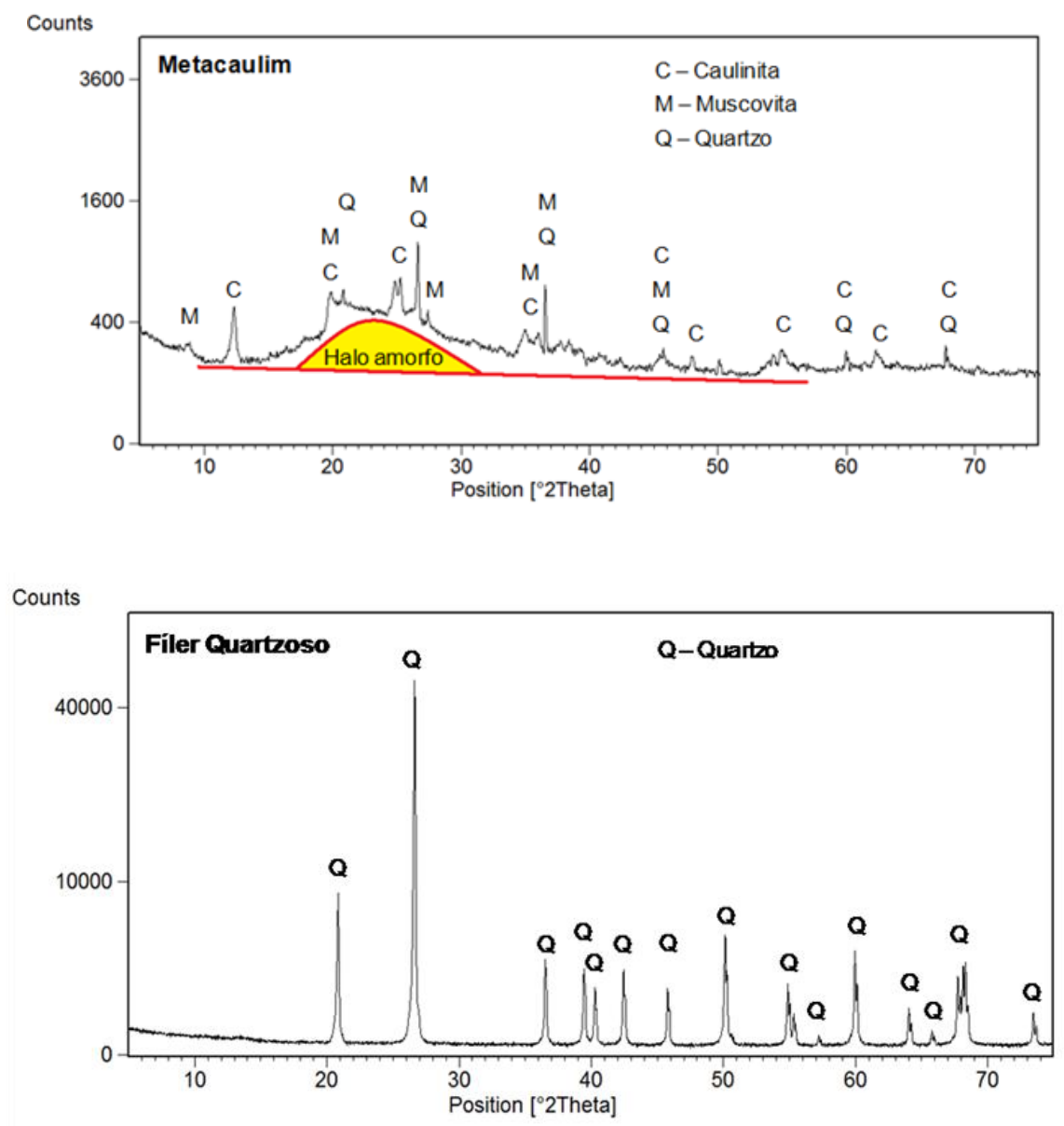

Figura 3: Difratogramas das amostras de adições minerais: metacaulim e fíler quartzoso

Como agregado miúdo utilizou-se areia natural proveniente de Balsa Nova, que tem massa específica de $2,63 \mathrm{~g} / \mathrm{cm}^{3}$, massa unitária de $1,54 \mathrm{~g} / \mathrm{cm}^{3}$ e módulo de finura de 2,34. O agregado graúdo utilizado foi basalto com dimensão máxima de $19 \mathrm{~mm}$ e massa específica de $2,64 \mathrm{~g} / \mathrm{cm}^{3}$.

O traço de concreto utilizado foi 1:0,1:2,25:3,00 (cimento:adição:areia:brita) e as adições foram acrescentadas com o teor de $10 \%$ do cimento, em massa. $O$ abatimento de tronco de cone foi mantido constante na faixa de $10 \pm 2 \mathrm{~cm}$ com auxílio de aditivo superplastificante policarboxilato. 
Antes de iniciar a carbonatação acelerada, foi adotado um processo de sazonamento que consistiu no método NORIE, apresentado em Pauletti [7]. O processo constitui em dispor os corpos de prova, em uma sala climatizada, com umidade e temperatura controladas e, quando a variação do peso do corpo de prova for menor que $0,10 \mathrm{~g}$ em 24 horas, a amostra está apta para o ensaio de carbonatação acelerada.

As amostras foram sujeitas à carbonatação acelerada em câmara de carbonatação com teor de $\mathrm{CO} 2$ de $5 \pm 0,5 \%$. A umidade relativa no interior do equipamento foi estabelecida em $65 \pm 1,0 \%$ e a temperatura foi mantida em $23 \pm 2{ }^{\circ} \mathrm{C}$. $\mathrm{O}$ tempo de permanencia dos corpos de prova na câmara de carbonatação acelerada foi de 12 semanas.

\subsection{Teste do "falso positivo" - concreto carbonatado \{sem cloretos\}}

Inicialmente o teste focou em confirmar a ocorrência do "falso positivo" na aspersão da solução de nitrato de prata no concreto carbonatado. Para isso, foram utilizados corpos de prova carbonatados e sem cloretos, um com adição de metacaulim (M1) e outro com adição de fíler de quartzo $\left(Q_{1}\right)$. Em ambos os casos, os corpos de prova foram seccionados ao meio sendo que na metade de uma face recém fraturada foi aplicada, por aspersão, uma solução de fenolftaleína (5 g de fenolftaleína para $276,15 \mathrm{~g}$ de álcool etílico e $150 \mathrm{~g}$ de água destilada) e na outra metade, aspergiu-se solução de nitrato de prata na concentração de $0,1 \mathrm{~mol} / \mathrm{L}$. A Figura 4 mostra um exemplo da aspersão meio a meio de indicadores químicos.

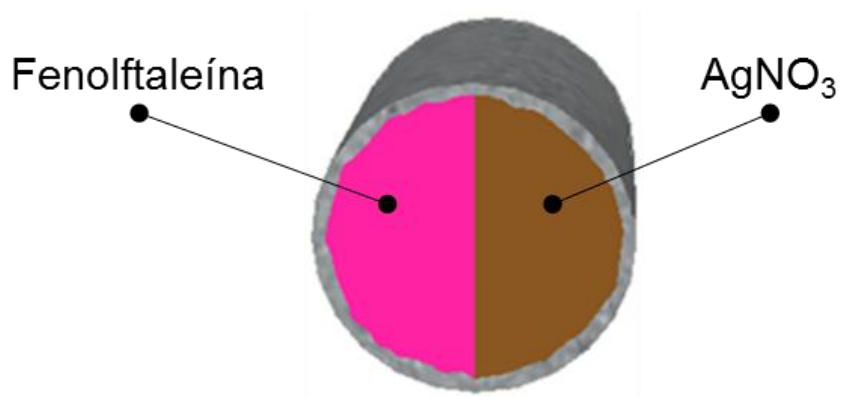

Figura 4: Corpo de prova carbonatado e livre de cloretos com metade da seção aplicada solução de AgNO3 e a outra metade com solução de fenolftaleína

\subsection{Teste da realcalinização com hidróxido de cálcio - concreto carbonatado \{sem cloretos\}}

Nesta parte do trabalho, o intuito foi analisar a validade da asperção de solução de hidróxido de cálcio na superfície recém fraturada do concreto como um tratamento prévio que evite a ocorrência do "falso positivo" quando se usa solução de AgNO3 para detectar a profundidade de penetração de cloretos.

Para isso, foram utilizados corpos de prova carbonatados e sem cloretos, como na seção anterior. Em ambos os casos, os corpos de prova foram seccionados ao meio sendo que em uma das faces recém fraturadas foi aplicada, por aspersão, a solução saturada de $\mathrm{Ca}(\mathrm{OH}) 2$ e na outra não. Em todos os casos foram utilizados três corpos de prova para cada caso de estudo. 
Em seguida, em uma metade da seção transversal de cada amostra seccionada, aplicou-se solução de fenolftaleína na proporção de $10 \mathrm{~g}$ de fenolftaleína para $700 \mathrm{~g}$ de álcool etílico para $300 \mathrm{~g}$ de água destilada, como indicado pelo documento [8, 9]. $\mathrm{Na}$ outra metade, aspergiu-se solução de nitrato de prata na concentração de 0,1 $\mathrm{mol} / \mathrm{L}$, como indicado por MECK; SIRIVIVATNANON [10]. A Figura 4 já mostrou o esquema da aspersão meio a meio de indicadores químicos.

Em seguida, realizou-se uma avaliação visual nas amostras. Se a fração com indicador químico de fenolftaleína adquirisse coloração vermelha carmim em toda sua extensão, a solução alcalina teria sido eficaz para aumentar o $\mathrm{pH}$ da frente de carbonatação. Ao mesmo tempo, a metade com solução de AgNO3 deveria mudar de cor em toda sua extensão, para a coloração marrom, ou seja, não deveria apontar o resultado "falso positivo" de presença de íons cloreto, pois todos os corpos de prova testados estavam livres de cloretos.

Caso tenha-se sucesso neste teste, o passo seguinte será testar o método em corpos de prova submetidos a penetração de cloretos, e neste caso, espera-se que a aspersão de solução de AgNO3 seja apropriada para detectar a profundidade da frente de penetração de íons cloretos.

\section{Resultados}

\subsection{Análises preliminares}

A Figura 5 mostra os resultados de resistência à compressão, aos 28 dias de cura úmida, dos dois traços de concreto deste experimento. Verifica-se que a resistência média à compressão dos corpos de prova com adição pozolânica foi de $78,5 \mathrm{MPa}$, e o com adição fíler de quartzo foi de 42,8 MPa.

A Figura 6 mostra os dados de absorção de água por sucção capilar para os mesmos traços, de modo que pode-se constatar que os corpos de prova dosados com metacaulim apresentaram sorvidade de água de $0,0046 \mathrm{~g} / \mathrm{cm}^{2}$.horas 0,5 , enquanto os moldados com fíler de quartzo obtiveram $0,0059 \mathrm{~g} / \mathrm{cm}^{2}$.horas0,5.

Observa-se que as amostras com adição de fíler quartzoso apresentaram menores resultados de resistência à compressão e maiores resultados de absorção por sucção capilar, quando comparados com as amostras com adição de metacaulim.Isso ocorre porque o fíler quartzoso contribui para a elevação da resistência do concreto apenas por meio do efeito físico (efeito fíler). Por outro lado, o metacaulim, além do efeito físico, possui também o efeito químico, ou seja, há a transformação do hidróxido de cálcio em C-S-H, que são materiais que conferem resistência mecânica ao concreto, e também acelera o processo de hidratação do cimento [11].

A evolução da carbonatação ao longo do tempo para estes dois concretos está representado na Figura 7, onde é possível observar que a amostra com adição de metacaulim apresentou maiores valores de profundidade de carbonatação do que a amostra com fíler quartzoso, com coeficientes de carbonatação de 1,96 e 1,34, respectivamente. 
MEDEIROS, M. H. F.; RÉUS, G. C.; PONTES, C. V., NITRATO DE PRATA COMO MÉTODO COLORIMÉTRICO PARA DETECÇÃO DA PENETRAÇÃO DE CLORETOS: ANÁLISE CRÍTICA. $3^{\circ}$ Simpósio Paranaense de Patologia das Construções ( $3^{\circ} \mathrm{SPPC}$ ), artigo 3SPPC1017, pp. 186 - 197, 2018. DOI: 10.4322/2526-7248.017

As amostras com fíler quartzoso obtiveram menor resistência à compressão e maior absorção de água por sucção capilar, o que indica que há mais facilidade de entrar $\mathrm{CO} 2$ nessa amostra. Apesar disso, essas amostras apresentaram menores valores de carbonatação em relação as amostras com adição de metacaulim. Para avaliar esses resultados, deve-se levar em conta o efeito fíler, que age em ambas as amostras e o efeito pozolânico que ocorre apenas nas amostra de metacaulim, pois o consumo do $\mathrm{Ca}(\mathrm{OH}) 2$ pela atividade pozolânica diminui a reserva alcalina do concreto, assim como demostrado para esta mesma amostra de metacaulim no trabalho de Medeiros et al. [12].

Neste caso, há um indício que o efeito do consumo do $\mathrm{Ca}(\mathrm{OH}) 2$ foi preponderante ao efeito fíler, pois a amostra com adição de metacaulim apresentou maiores valores do avanço da carbonatação.

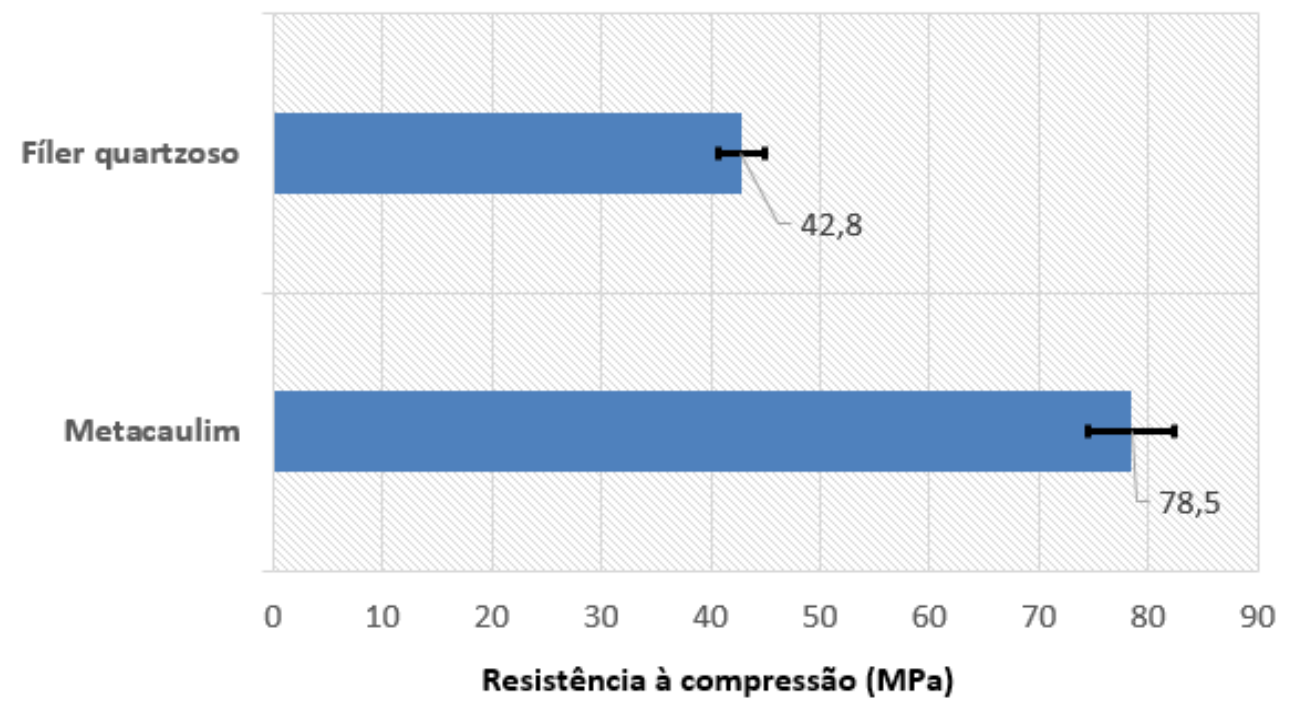

Figura 5: Resistência à compressão dos corpos de prova com adição fíler quartzoso e metacaulim

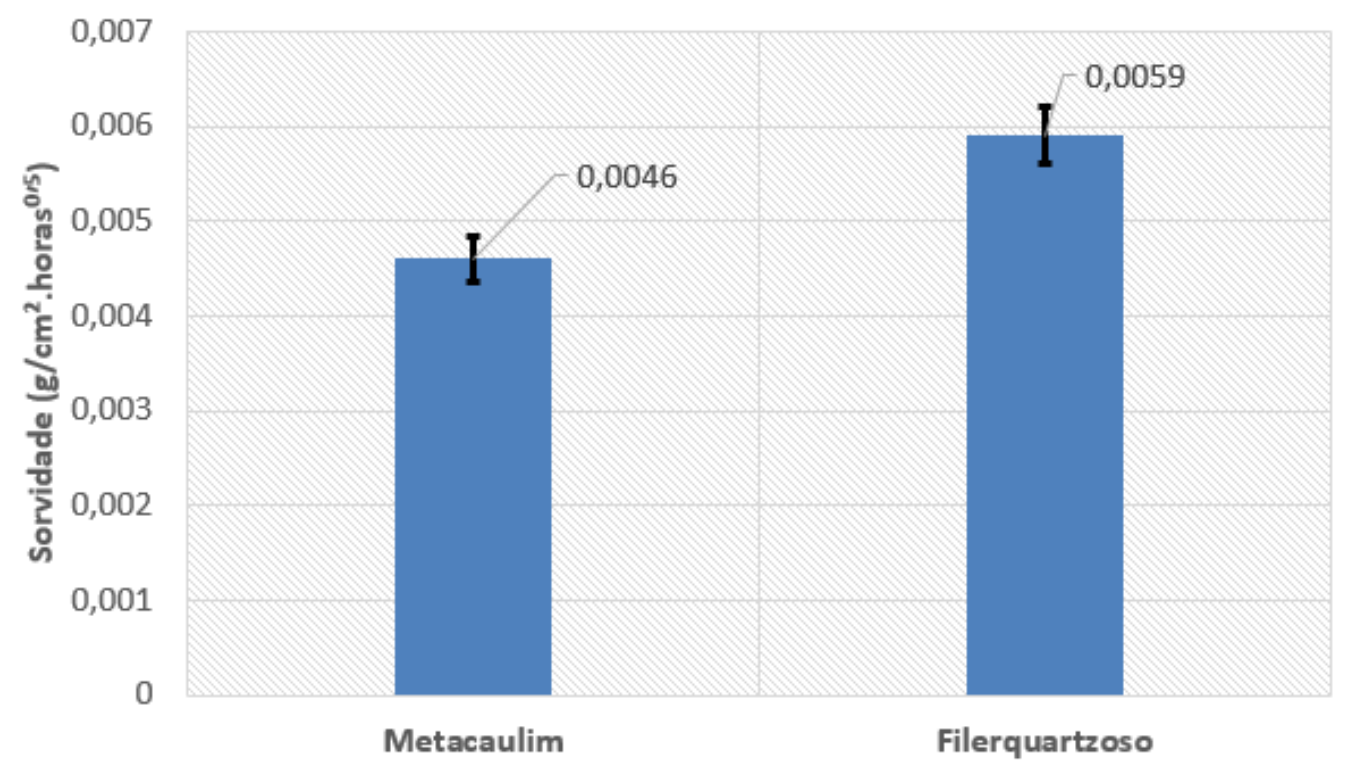

Figura 6: Absorção de água por sucção capilar dos corpos de prova com adição fíler quartzoso e metacaulim 


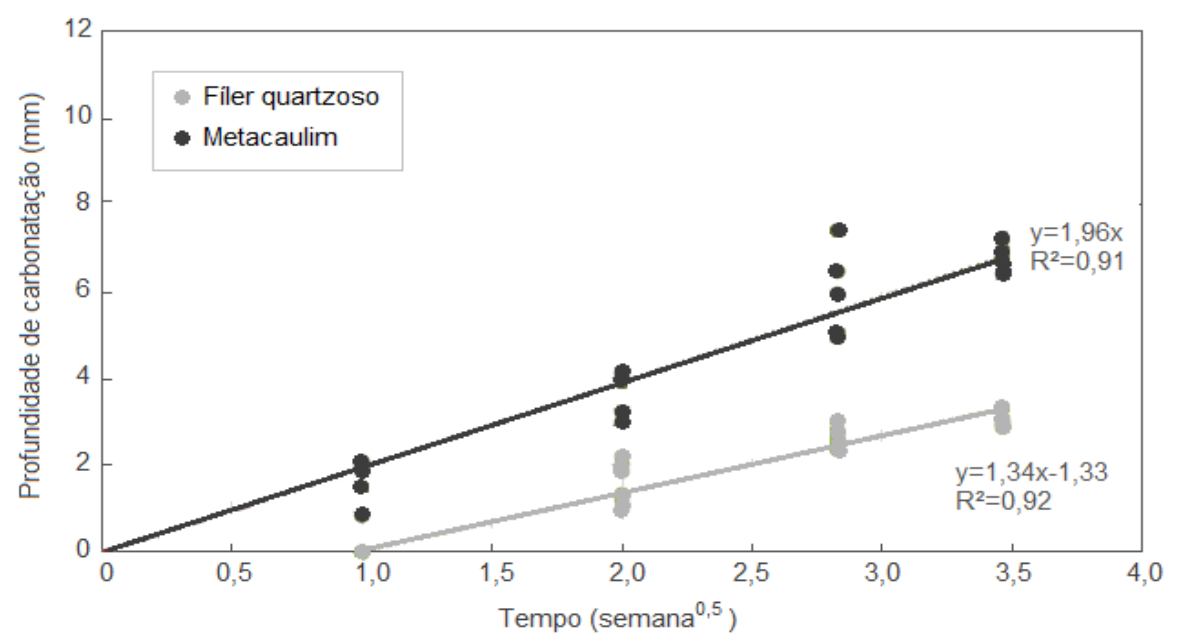

Figura 7: Carbonatação aceleradas das amostras com metacaulim e fíler quartzoso $\left(5 \pm 0,5 \%\right.$ de CO2, U.R. de $65 \pm 1,0 \%$ e temperatura de $\left.23 \pm 2{ }^{\circ} \mathrm{C}\right)$

\subsection{Teste do "falso positivo" - concreto carbonatado \{sem cloretos\}}

A Figura 8 evidencia a ocorrência do "falso positivo" quando se faz uso de aspersão de solução de nitrato de prata no concreto carbonatado. Ficou evidente que a frente de carbonatação influenciou a mudança de cor neste método colorimétrico de modo a indicar presença de cloretos na peça de concreto que nem tinha sido submetida a exposição aos íons cloretos. Este resultado está de acordo com o relatado na pesquisa de Jucá [3] e é um importante fator a ser considerado para o emprego no método.

O resultado da Figura 8 é o motivo pelo qual o método de aspersão de solução de AgNO3 não é consagrado em trabalhos de campo como ocorre com a aspersão de fenolftaleína que é classicamente usada nos diagnósticos de inspeção de campo para justificar a corrosão de armaduras pela chegada da frente de carbonatação nas armaduras. No caso da solução de AgNO3, existe o complicador de a carbonatação introduzir a incerteza quanto a mudança de cor neste método colorimétrico.

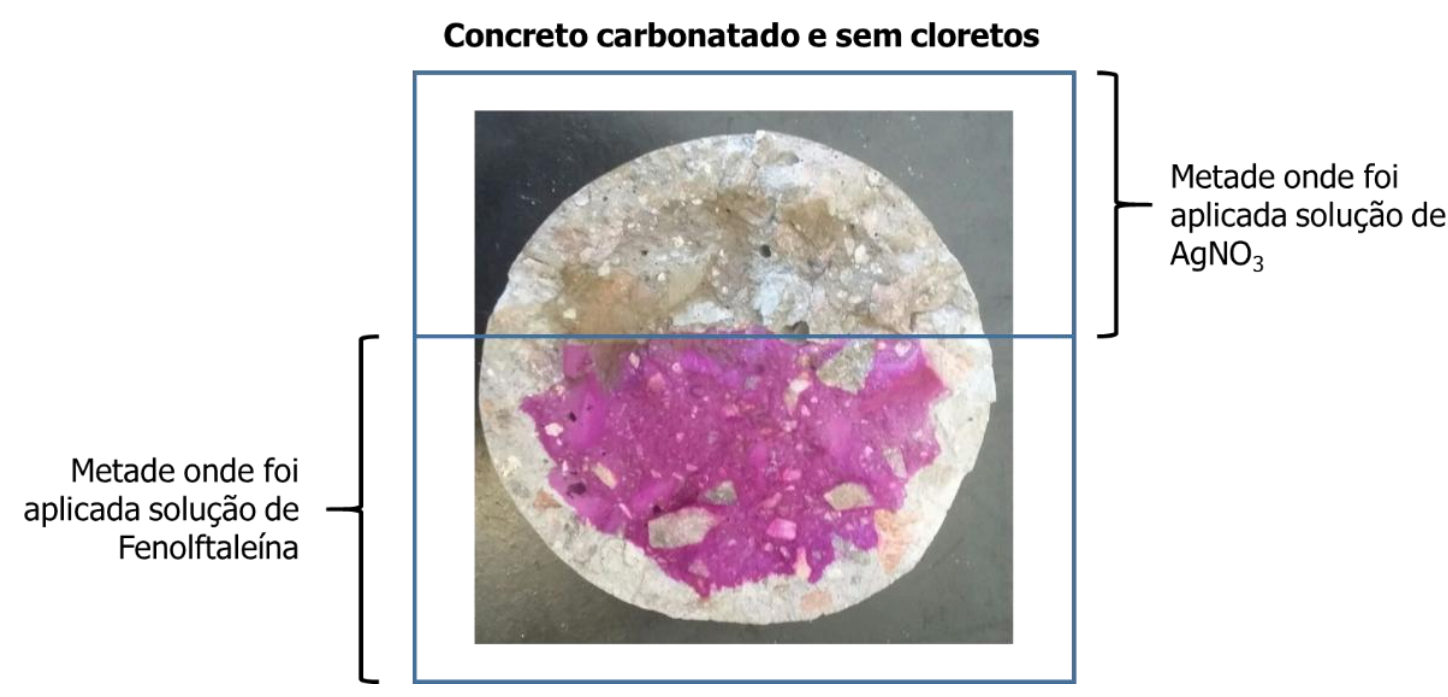

Figura 8: Corpo de prova carbonatado e livre de cloretos com metade da seção aplicada solução de AgNO3 e a outra metade com solução de fenolftaleína 
MEDEIROS, M. H. F.; RÉUS, G. C.; PONTES, C. V., NITRATO DE PRATA COMO MÉTODO COLORIMÉTRICO PARA DETECÇÃO DA PENETRAÇÃO DE CLORETOS: ANÁLISE CRÍTICA. $3^{\circ}$ Simpósio Paranaense de Patologia das Construções (30 SPPC), artigo 3SPPC1017, pp. 186 - 197, 2018. DOI: 10.4322/2526-7248.017

O método de aspersão de solução de nitrato de prata tem sido usado em trabalhos que envolvem ensaios de migração de cloretos, onde o concreto sai do processo de cura e é submetido ao ensaio [13, 14, 15, 16]. Nestes casos, a aplicação do método colorimétrico é factível, pois os corpos de prova não estão carbonatados e a medida de penetração de cloretos pela mudança de cor é válida. Porém, em estruturas reais que necessitem passar por trabalhos de inspeção, o método se mostra ineficiente pelo fato de que estas estruturas apresentam certo avanço da frente de carbonatação associada ou não a contaminação por cloretos. Este foi o motivo que o método de aspersão de solução de nitrato de prata não foi usado nos trabalhos de Medeiros et al. e Medeiros Junior et al. [16, 17].

\subsection{Teste da realcalinização com hidróxido de cálcio - concreto carbonatado \{sem cloretos\}}

A Figura 9 apresenta os resultados das tentativa de neutralizar o efeito da carbonatação no teste com o nitrato de prata utilizando hidróxido de cálcio. $O$ raciocínio desta parte do experimento foi o de tentar aspergir, na superfície de concreto recém fraturada, uma solução aquosa saturada com $\circ \mathrm{Ca}(\mathrm{OH}) 2$, que é o produto mais presente na solução de poro do próprio concreto quando não está carbonatado.

Nesta etapa, todas as amostras estavam carbonatadas e sem contaminação por cloretos. Verifica-se na Figura 9 que a aspersão de solução aquosa saturada como $\mathrm{Ca}(\mathrm{OH}) 2$ não foi capaz de interferir na viragem de cor dos métodos colorimétricos de fenolftaleína e de nitrato de prata, indicando que o método de realcalinizar com $\mathrm{Ca}(\mathrm{OH}) 2$ não é eficaz para evitar o "falso positivo" no método colorimétrico de AgNO3 para mensurar a penetração de cloretos livres no interior do concreto armado.

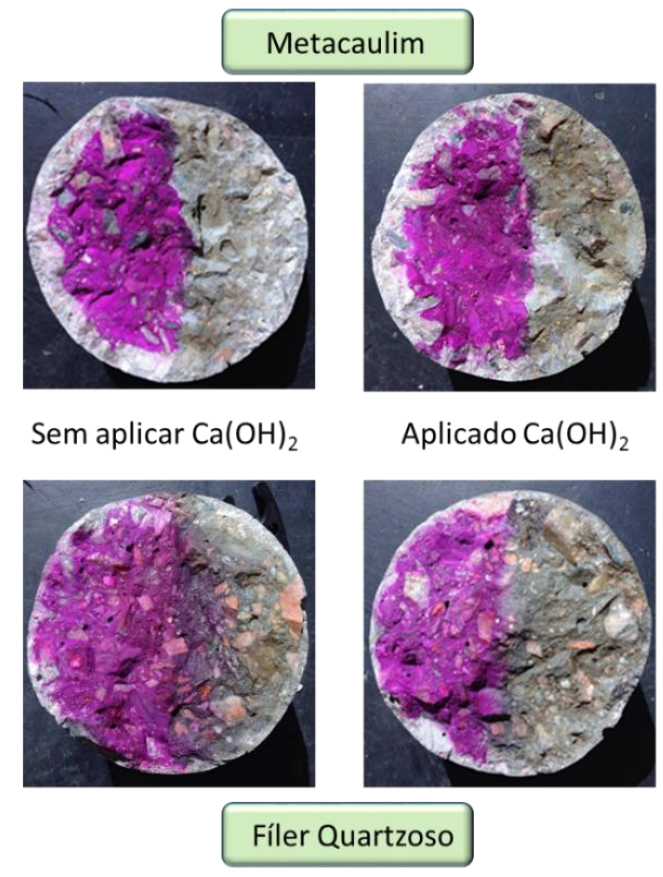

Figura 9: Corpos de prova carbonatados com (a) adição de metacaulim e aspersão de solução de $\mathrm{Ca}(\mathrm{OH}) 2$; (b) adição de fíler quartzoso e aspersão de solução de $\mathrm{Ca}(\mathrm{OH}) 2$. 
MEDEIROS, M. H. F.; RÉUS, G. C.; PONTES, C. V., NITRATO DE PRATA COMO MÉTODO COLORIMÉTRICO PARA DETECÇÃO DA PENETRAÇÃO DE CLORETOS: ANÁLISE CRÍTICA. $3^{\circ}$ Simpósio Paranaense de Patologia das Construções (30 SPPC), artigo 3SPPC1017, pp. 186 - 197, 2018. DOI: 10.4322/2526-7248.017

O mesmo comportamento foi observado tanto para o concreto com adição de metacaulim, como para as amostras com adição de fíler quartzoso. Ou seja, o hidróxido de cálcio não foi capaz de inibir a interferência da carbonatação no método de colorimétrico com aspersão de nitrato de prata. É provável que isso tenha ocorrido em função da baixa concentração de hidroxila na solução saturada como hidróxido de cálcio. Isso ocorre devido a baixa solubilidade do $\mathrm{Ca}(\mathrm{OH}) 2$, conforme relatado por Réus [18].

\section{Conclusões}

Com base nos resultados desta pesquisa conclui-se que:

- O método colorimétrico de aspersão de solução de nitrato de prata para detectar a profundidade de penetração de cloretos apresenta tendência a acusar "falso positivo" quando o concreto está carbonatado;

- A solução aquosa saturada de $\mathrm{Ca}(\mathrm{OH}) 2$ não é capaz de inibir a influência da carbonatação no método colorimétrico de nitrato de prata;

- Com base no experimento realizado, pode-se concluir que o método de aspersão de solução de AgNO3, nos moldes do procedimento empregado neste artigo, não é viável para ser usado em trabalhos de inspeção em campo, em que as edificações em serviço estejam em processo simultâneo de interação como o dióxido de carbono e com a contaminação por cloretos por alguma fonte externa.

O Grupo de pesquisa de Patologia e Recuperação das Construções, sediado na Universidade Federal do Paraná (UFPR) e liderado pelo Professor Marcelo Medeiros, continua com esta linha de pesquisa tentando por outros meios encontrar um caminho para viabilizar o emprego deste método colorimétrico que pode agregar praticidade e economia para o diagnóstico de estruturas de concreto armado inseridos em ambientes contaminados por cloretos.

\section{Agradecimentos}

Os autores registram o seu agradecimento para a Universidade Federal (UFPR) do Paraná, Fundação Araucária e Conselho Nacional de Desenvolvimento Científico e Tecnológico (CNPq) por ter proporcionado o suporte necessário para 0 desenvolvimento desta pesquisa.

\section{Referências}

[1] FRANÇA, C. B. Avaliação de cloretos livres em concretos pelo método de aspersão de solução de nitrato de prata. 2011. Dissertação (Mestrado) Universidade Católica de Pernambuco, Recife, 2011.

[2] MOTA, A. C. M. Avaliação da presença de cloretos livres em argamassas através do método colorimétrico de aspersão da solução de nitrato de prata. 2011. Dissertação (Mestrado). Escola Politécnica da Universidade de Pernambuco, Recife, 2011. 
MEDEIROS, M. H. F.; RÉUS, G. C.; PONTES, C. V., NITRATO DE PRATA COMO MÉTODO COLORIMÉTRICO PARA DETECÇ̃̃̃O DA PENETRAÇÃO DE CLORETOS: ANÁLISE CRITIICA. $3^{\circ}$ Simpósio Paranaense de Patologia das Construções ( $3^{\circ} \mathrm{SPPC}$ ), artigo 3SPPC1017, pp. 186 - 197, 2018. DOI: 10.4322/2526-7248.017

[3] JUCÁ, T. R. P. Avaliação de cloretos livres em concretos e argamassas de cimento Portland pelo método de aspersão de solução de nitrato de prata. 2002. Dissertação (Mestrado), Universidade Federal de Goiás, Goiânia, 2002.

[4] MEDEIROS, M. H. F.; HOPPE FILHO, J.; HELENE, P. Influence of the slice position on chloride migration tests for concrete in marine conditions. Marine Structures, v. 22, p. 128-141, 2009b.

[5] NT BUILD 492. Method: Concrete, mortar and cement-based repair materials: Chloride migration coefficient from non-steady-state migration experiments. NordTest, Finland, 1999.

[6] ASSOCIAÇÃO BRASILEIRA DE NORMAS TÉCNICAS. NBR 15895: Materiais pozolânicos - Determinação do teor de hidróxido de cálcio fixado - Método Chapelle modificado. Rio de Janeiro, 2010.

[7] PAULETTI, C Análise comparativa de procedimentos para ensaios acelerados de carbonatação. Dissertação (Mestrado), Universidade Federal do Rio Grande do Sul, Porto Alegre, 2004.

[8] RÉUNION INTERNATIONALE DES LABORATORIES D'ESSAIS DE RECHERCHES SUR LES MATÉRIAUX ET LES CONSTRUCTIONS - RILEM Measurement of hardened concrete carbonation depth: RILEM CPC-18. Materials and Structures, v. 21, n. 6, p. 453-55, 1988.

[9] CASTRO, A. Influência das adições Minerais na Durabilidade do Concreto Sujeito à Carbonatação. Dissertação (Mestrado), Escola de Engenharia Civil, Universidade Federal de Goiás, Goiânia, 2003.

[10] MECK, E.; SIRIVIVATNANON, V. Field indicator of chloride penetration depth. Cement and Concrete Research, v. 33, p. 1113-1117, 2003.

[11] CUNHA, M. F.; FORTI, B. A.; SILVA, B. I. Tendências da normalização de metacaulim pra uso em concretos. Anais: IBRACON 2010, p. 46. Ceará, 2010.

[12] MEDEIROS, M. H. F.; RAISDORFER, J. W.; HOPPE FILHO, J. Influência da sílica ativa e do metacaulim na velocidade de carbonatação do concreto: relação com resistência, absorção e relação a/c. Ambiente Construído (Online), v. 17, p. 125-139, 2017.

[13] LUPING, T.; NILSSON, L. Rapid Determination of the chloride diffusivity in concrete by applying an electrical field. ACI Materials Journal, v. 89, n. 1, p. 4953, 1992.

[14] MEDEIROS, M. H. F. Contribuição ao estudo da durabilidade de concretos com proteção de superficial frente à ação de íons cloreto. 2008. Tese (Doutorado). Escola Politécnica da Universidade de São Paulo, São Paulo, 2008.

[15] MEDEIROS, M. H. F.; HELENE, P. Surface treatment of reinforced concrete in marine environment: Influence on chloride diffusion coefficient and capillary water absorption. Construction \& Building Materials, v. 23, p. 1476-1484, 2009a.

[16] MEDEIROS, M. H. F.; GOBBI, A.; RÉUS, G. C.; HELENE, Paulo. Reinforced concrete in marine environment: Effect of wetting and drying cycles, height and positioning in relation to the sea shore. Construction \& Building Materials, v. 44, p. 452-457, 2013. 
MEDEIROS, M. H. F.; RÉUS, G. C.; PONTES, C. V., NITRATO DE PRATA COMO MÉTODO COLORIMÉTRICO PARA DETECÇÃO DA PENETRAÇÃO DE CLORETOS: ANÁLISE CRÍTICA. $3^{\circ}$ Simpósio Paranaense de Patologia das Construções (3० SPPC), artigo 3SPPC1017, pp. 186 - 197, 2018. DOI: 10.4322/2526-7248.017

[17] MEDEIROS JUNIOR, R. A.; LIMA, M. G.; BRITO, P. C.; MEDEIROS, M. H. F. Chloride penetration into concrete in an offshore platform-analysis of exposure conditions. Ocean Engineering, v. 103, p. 78-87, 2015.

[18] RÉUS, G. C. Realcalinização química como meio de recuperação de estruturas de concreto armado carbonatadas. 2017. 104 p. Dissertação (Mestrado em Construção Civil) - Universidade Federal do Paraná, Curitiba, 2017. 